\title{
Relationships between Gross Motor Abilities and Sensory Processing in Children Aged 18 to 36 Months
}

\author{
Eri TAKahashi, MSc, $\mathrm{PT}^{1}$, Osamu NitTA, PhD, $\mathrm{PT}^{2}$, Kenji TAKaKI, MSc, $\mathrm{PT}^{3}$ and Yuichi Toba, Diploma ${ }^{4}$ \\ ${ }^{1)}$ Faculty of Health Sciences, Tohoku Fukushi University, Japan \\ ${ }^{2)}$ Faculty of Health Sciences, Tokyo Metropolitan University, Japan \\ ${ }^{3)}$ Faculty of Health Sciences, Mejiro University, Japan \\ ${ }^{4)}$ Pyonsuke Kids House Authorized Daycare Center, Japan
}

\begin{abstract}
OBJECTIVE: We investigated the relationship between gross motor abilities and sensory processing in typically developing children. METHOD: Participants included children aged 18 to 36 months $(\mathrm{N}=48$ ). All participants were full-term infants. We assessed gross motor abilities based on the Gross Motor Function Measure (GMFM), and sensory processing characteristics based on the Infant/Toddler Sensory Profile (ITSP). The gross motor ability index was calculated using GMFM score which was estimated from the age. Pearson's product moment correlation coefficients were used to examine the relationships between the gross motor ability indexes and ITSP section scores. RESULTS: Our findings showed that gross motor ability may be related to oral sensory processing. The children who were more responsive to oral sensory processing tended to exhibit gross motor abilities below the standard for that age. CONCLUSION: Gross motor abilities were related with sensory processing, especially oral sensory processing, in children aged 18 to 36 months.
\end{abstract}

Key words: gross motor abilities, sensory processing, full-term infants

(Phys Ther Res 24: 106-111, 2021)

\section{$\mathbf{S}$} sponse to single sensory stimuli (e.g., sound or light), processing mechanisms within a specific sensory system, and integration of multiple sensory processing systems ${ }^{1)}$. These processes form the basis of learning, cognition and behavior in children ${ }^{2}$. Typically developing children aged 1 to 3 years tend to acquire more sensory stimuli than children aged $>3$ years $^{3)}$. As children acquire more sensory stimuli and information, they experience habitation and sensitization $^{3)}$. Habitation and sensitization permit children to generate appropriate adaptive responses to stimuli in the environment ${ }^{3)}$. Children with developmental disabilities, such as autism spectrum disorder (ASD) and attention deficit hyperactivity disorder (ADHD), differ in sensory responses

Received: May 15, 2020

Accepted: October 2, 2020

Advance Publication by J-STAGE: November 25, 2020

Correspondence to: Eri Takahashi, Faculty of Health Sciences, Tohoku Fukushi University, Japan, 6-149-1 Kunimigaoka, Aoba-ku, Sendai, Miyagi 989-3201, Japan

\# e-mail: eri-t@tfu-mail.tfu.ac.jp

doi: 10.1298/ptr.E10051 from typically developing children ${ }^{4)}$. As the sensory processing characteristics of typically developing children are distributed on the bell curve, some of them have sensory processing characteristics similar to those of cohorts with developmental disabilities ${ }^{5}$. Ahn et al. ${ }^{2)}$ reported that $5 \%$ of kindergarten children have sensory processing disorders.

Correct sensory processing is important during motor development because motor development is largely dependent on experiences, particularly active trial-and-error experiences ${ }^{6}$. Currently, there are two common theoretical frameworks on motor development, the dynamic systems theory $(\mathrm{DST})^{7-9)}$, and the neuronal group selection theory $(\mathrm{NGST})^{10)}$. In these theoretical frameworks, it is thought that experiences and correct sensory processing are essential for motor development. Correct sensory processing enables an adaptive response, the development of postural control, coordinated movement, motor development, and arrangement of the awake-orientation status ${ }^{11)}$. Previous studies have reported that motor development and sensory processing are related in preterm infants ${ }^{11,12}$. As mentioned above, the sensory processing characteristics are distributed on the bell curve among full-term children ${ }^{5)}$. However, only 
a few studies have investigated the relationship between motor development and sensory processing among fullterm children who demonstrated typical developmental patterns. Children aged 18 to 36 months spread their movement space after gaining the ability to walk stable. In addition, sensory processing characteristics might exhibit differences among individuals. Therefore, the purpose of the current study was to investigate the relationship between gross motor abilities and sensory processing in children aged 18 to 36 months.

\section{Methods}

\section{Participants}

Children aged 18 to 36 months were recruited through leaflet announcements from four nursery schools. Participants were excluded if they were premature or low birthweight infants, or if they had been diagnosed with developmental disorders, such as developmental coordination disorder (DCD), ASD, ADHD, intellectual disorder (ID), cerebral palsy $(\mathrm{CP})$, or neurological or psychiatric disorders.

Prior to the study, written informed consent was obtained from the adult parents of each participating child in a manner approved by the research ethics committee of the Tokyo Metropolitan University Arakawa Campus (approval number 19059).

\section{Instruments}

Two standardized measuring instruments were used in the current study. We assessed sensory processing characteristics based on the Infant/Toddler Sensory Profile $(\text { ITSP })^{13)}$, and gross motor abilities were assessed based on the Gross Motor Function Measure (GMFM) ${ }^{14)}$.

\section{Japanese Version of ITSP $(J-I T S P)^{15)}$}

The ITSP is a standardized parent-reported questionnaire that is used to assess sensory processing characteristics in infants and toddlers. There are two types of ITSP questionnaires: a) the first is for children aged 0 to 6 months, and b) the second is for children aged 7 to 36 months. In the current study, we used the ITSP for children aged 7 to 36 months according to the participants' age. In this case, the ITSP consisted of 48 items. Parents or caregivers rated the frequency of their child's sensory processing characteristics and behaviors based on a five-point Likert scale: 5 = always, 4 = frequently, 3 = occasionally, 2 = seldom, and $1=$ never. Items were grouped in the following five sensory system sections: auditory processing (13 items), visual processing ( 7 items), tactile processing (15 items), vestibular processing ( 6 items), and oral sensory processing ( 7 items). Three items refer to general processing types. The scores for the five sections were calculated by summation of all the points for all the items in a section. The reliabilities of the J-ITSP for various composite scores ranged from $.56-.90^{15}$.

\section{GMFM}

The GMFM is a standardized observational instrument designed to measure gross motor abilities over time for children with $\mathrm{CP}$ aged 5 months to 16 years. Because the items included in the GMFM are typical for normal developmental milestones in 5 year old children, we used GMFM to measure gross motor abilities. There are two versions of GMFM: a) the first one is the original measure with 88 items (GMFM-88) and b) the second is a measure with 66 items (GMFM-66). The GMFM-88 has been validated in populations other than $\mathrm{CP}$, such as Down syndrome ${ }^{16,17)}$, traumatic brain injury ${ }^{18)}$, Fukuyama congenital muscular dystrophy ${ }^{19)}$, and osteogenesis imperfecta ${ }^{20)}$. The items are scored on a four-point ordinal scale: $0=$ cannot initiate, 1 = initiates, 2 = partially completes item, 3 = completes item independently ${ }^{14}$. We adopted the GMFM-66 that was developed based on Rasch analysis in an attempt to improve the interpretability and clinical usefulness of the GMFM-88 ${ }^{21)}$. GMFM-66 has good reliability and validity $(\text { intraclass correlation }[\mathrm{ICC}]=.96)^{22}$ ). Furthermore, we adopted the 'basal-ceiling' approach of GMFM-66 (GMFM-66 B\&C). During the administration of GMFM-66 $\mathrm{B} \& \mathrm{C}$, testing began once three consecutive " $3 \mathrm{~s}$ " ("completes") had been scored, and stopped when three consecutive "0s" ("does not initiate") had been scored. To complete the test, at least 15 items should be tested ${ }^{14)}$. GMFM-66 B\& $\mathrm{C}$ has good reliability and validity with GMFM-66 (ICC = $.99,95 \%$ confidence interval $=.98-.99)^{23)}$. The individual item scores of GMFM-66 are converted to an interval score using a computer program called "GMFM App+" ${ }^{14)}$. The GMFM-66 score (GMFM score) ranges from 0 to 100 . The GMFM score of typically developing child aged 5 years is expected to be 100 .

Prior to the study, we examined the test-retest reliability of GMFM-66 B\&C with 11 children. Eleven children were randomly elected from the participants. One rater assessed the GMFM-66 B\&C following a 2-3 week interval. As a result, ICC was excellent ${ }^{24)}(\operatorname{ICC}(1,2)=.97)$. There was a significant and strong correlation between the GMFM score and age in months $(r=.751, \mathrm{p}<.01)$. Therefore, we confirmed the reliability and validity in the assessment of GMFM in typically developing children, and it was possible to assess typically developing children based on the GMFM.

\section{Statistical Analysis}

All statistical analyses were conducted using IBM SPSS Statistics (Version 22.0; IBM Corp., Armonk, NY). Descriptive statistics were used to characterize the basic properties of the observed variables. In order to remove the influence of age, the gross motor ability index was adopted. Single linear regression models were applied to calculate 
Table 1. Mean Scores for J-ITSP Sensory Systems Sections

\begin{tabular}{llcl}
\hline \multicolumn{2}{c}{ Sensory systems sections } & Mean & SD \\
\hline Auditory & (13 items) & 16.1 & 5.0 \\
Visual & (7 items) & 14.4 & 5.1 \\
Tactile & (15 items) & 24.9 & 5.8 \\
Vestibular & (6 items) & 12.7 & 3.1 \\
Oral sensory & (7 items) & 11.3 & 4.3 \\
\hline
\end{tabular}

Note. SD = standard deviation, J-ITSP = Japanese version of Infant/Toddler Sensory Profile.

Table 2. Rerationship between J-ITSP Section Scores and Age in Months

\begin{tabular}{llcc}
\hline \multirow{2}{*}{ Sensory systems sections } & \multicolumn{2}{c}{ Age in Months } \\
\cline { 3 - 4 } & & $\mathrm{r}$ & $\mathrm{p}$ \\
\hline Auditory & (13 items) & -0.159 & 0.280 \\
Visual & (7 items) & 0.128 & 0.385 \\
Tactile & (15 items) & -0.166 & 0.261 \\
Vestibular & (6 items) & 0.185 & 0.208 \\
Oral sensory & (7 items) & -0.140 & 0.343 \\
\hline
\end{tabular}

Note. J-ITSP = Japanese version of Infant/Toddler Sensory Profile, $r=$ Pearson's product moment correlation coefficirnts.

the standard GMFM scores estimated from the ages of participants. The independent variable was age in months, whereas the GMFM score was examined as the dependent variable in the regression analyses. The GMFM scores were calculated with the use of the estimated regression formula. The gross motor ability index was defined as the difference between the assessed and estimated GMFM scores. If the gross motor ability index is zero, the gross motor ability is standard for the age. A positive gross motor ability index is above the standard for the age, whereas a negative gross motor ability index is below the standard for the age. Pearson's product moment correlation coefficients were used to examine the relationships between age in months, gross motor abilities and sensory processing characteristics. Spearman's rank correlation coefficients were used to examine the relationships between gross motor abilities and ITSP item points. Correlation coefficients were interpreted as follows: strong correlation $(\mathrm{r}>.75)$, moderate correlation $(r=.50-.75)$, mild correlation $(r=.25-.50)$, and weak correlation $(r<.25)$. Significance was set at $p<.05$.

\section{Results}

\section{Demographic Characteristics of Participants}

Forty-eight participants who demonstrated typical developmental patterns were enrolled in the current study. The participants' mean age was 27.1 months (standard de-

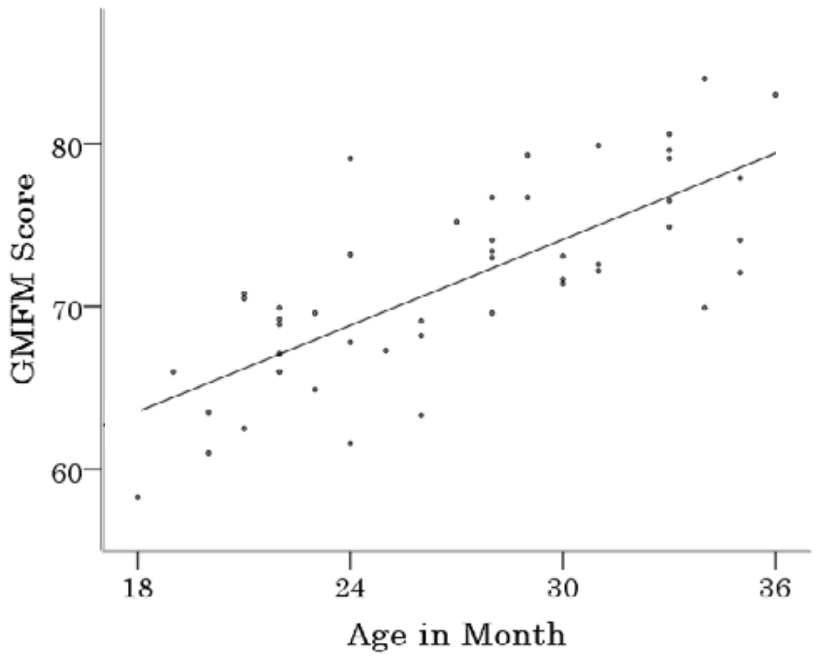

Figure 1. Scatter plot and linear regression analysis conducted to investigate the association between the GMFM score and age in months.

Note. GMFM = Gross Motor Function Measure.

viation $[\mathrm{SD}]=5.1$, range $18-36$ months), with 27 boys and 21 girls. The mean height was $85.2 \mathrm{~cm}(\mathrm{SD}=4.4$, range $74.1-94.9 \mathrm{~cm})$, mean weight was $12.0 \mathrm{~kg}(\mathrm{SD}=1.5$, range 9.2-14.8 kg), mean gestational age was 39.2 weeks ( $\mathrm{SD}=$ 1.1 , Range $37-41$ weeks), and the mean birth weight was $3164.1 \mathrm{~g}(\mathrm{SD}=389.7$, range $2500-4300 \mathrm{~g})$.

\section{J-ITSP Score}

The mean scores for the J-ITSP sensory system sections are displayed in Table 1 . There were no significant relationships between the J-ITSP section scores and age in months (See Table 2).

\section{GMFM Score}

The participants' mean GMFM score was 71.6 ( $\mathrm{SD}=$ 6.0, range 58-84). By conducting single linear regression with age in months as the independent variable and the GMFM score as the dependent variable, the following significant regression formula was obtained: GMFM score $=$ $47.668+0.882 \times$ age in months $\left(\mathrm{p}<.01, \mathrm{r}^{2}=.564\right.$, see Figure 1).

Relationship between the Gross Motor Ability Index and Sensory Processing

There was a significant relationship between the gross motor ability index and oral sensory processing $(\mathrm{p}=.045)$. There were no significant relationships between the gross motor ability index and the other J-ITSP section scores (See Table 3). Among the oral sensory processing items, item 42 ("My child licks / chews on nonfood objects."), was significantly associated with the gross motor ability index ( $\mathrm{p}=$ .030 , see Table 4 ). Figure 2 shows the distribution of item 42. The median is 1.0. The highest frequency is $31(64.6 \%)$ for 1 within a five-point Likert scale. The distribution of 
item 42 is the most common pattern. Twenty nine of 48 items $(60.9 \%)$ showed similar distribution.

\section{Discussion}

We investigated the relationship between gross motor abilities and sensory processing in full-term children who demonstrated typical developmental patterns (aged 18 to 36 months). Our findings showed that gross motor ability may be related to oral sensory processing. Children who were more responsive to oral sensory processing tended to exhibit gross motor abilities below the usual standard for that age.

Oral sensory processing is important in children. In particular, the mouth is a major source of receiving information during the early developmental period ${ }^{3)}$. The mouth and face are structures that occupy most of the area of the sensory homunculus, which shows the sensory distribution

Table 3. Rerationship between Gross Motor Ability Index and J-ITSP Section Scores

\begin{tabular}{lcc}
\hline \multirow{2}{*}{$\begin{array}{c}\text { Sensory sys- } \\
\text { tems sections }\end{array}$} & \multicolumn{2}{c}{$\begin{array}{c}\text { Gross Motor } \\
\text { Ability Index }\end{array}$} \\
\cline { 2 - 3 } & $\mathrm{r}$ & $\mathrm{p}$ \\
\hline Auditory & -0.172 & 0.242 \\
Visual & -0.284 & 0.051 \\
Tactile & 0.037 & 0.804 \\
Vestibular & -0.049 & 0.742 \\
Oral sensory & $-0.291 *$ & 0.045 \\
\hline
\end{tabular}

Note. Gross Motor Ability Index = the defference between assessed GMFM score and estimated GMFM score, GMFM = Gross Motor Function Measure, J-ITSP = Japanese version of Infant/Toddler Sensory Profile, $r=$ Pearson's product moment correlation coefficirnts. of the body in the cerebral cortex ${ }^{25)}$.

Furthermore item 42 ("My child licks / chews on nonfood objects.") related to sensory seeking ${ }^{13)}$ and exploratory behaviors. Exploratory behavior through oral sensory processing is also important during childhood development. In early development, sucking provides infants with essential nutrients, the feeling of well-being, and the sense of security $^{26)}$. As infants develop, they seek and explore through oral sensory processing based on mouthing behaviors, such as sucking their fingers and any objects that come in contact with their mouths. Oral sensory processing in combination with visual processing and tactile processing allows children to explore their environments ${ }^{27,28)}$.

The frequency of mouthing behavior in children may be affected by age $\mathrm{e}^{26,29,30)}$. Tulve et al. ${ }^{31)}$ reported that the frequency of mouthing behavior decreased in children aged $\leq$ 2 years. Conversely, Bearmer et al. ${ }^{32}$ observed mouthing behaviors, such as those related to the placement of clothes and plastics to their mouths in children aged $>7$ years. The frequency of exploratory behaviors through oral sensory processing decreases with age; however, this may vary

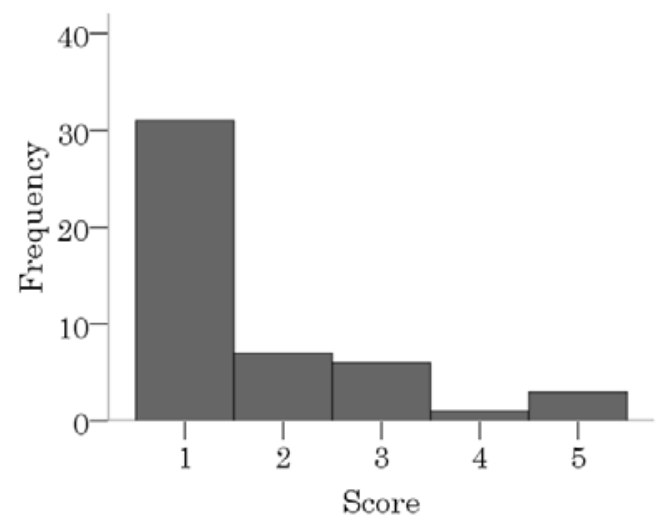

Figure 2. Histogram of J-ITSP Item 42. Note. J-ITSP = Japanese version of Infant/Toddler Sensory Profile.

Table 4. Rerationship between Gross Motor Ability Index and J-ITSP Items in Oral Sensory Processing

\begin{tabular}{lcc}
\hline \multirow{2}{*}{ J-ITSP Items in Oral Sensory Processing } & \multicolumn{2}{c}{$\begin{array}{c}\text { Gross Motor } \\
\text { Ability Index }\end{array}$} \\
\cline { 2 - 3 } & $\mathrm{r}_{\mathrm{s}}$ & $\mathrm{p}$ \\
\hline 42 My child licks / chews on nonfood objects. & $-0.314^{*}$ & 0.030 \\
43 My child mouths objects. & -0.269 & 0.064 \\
44 My child does not notice food and drink remain on his / her lip. & 0.164 & 0.264 \\
45 My child eats a few kinds of foods. & 0.031 & 0.832 \\
46 My child resists having teeth brushed. & -0.243 & 0.096 \\
47 My child resists to drink from a glass. & 0.047 & 0.749 \\
48 My child resists to try new kinds of food. & -0.009 & 0.952 \\
\hline
\end{tabular}

Note. Gross Motor Ability Index = the defference between assessed GMFM score and estimated GMFM score, GMFM = Gross Motor Function Measure, J-ITSP = Japanese version of Infant/ Toddler Sensory Profile, $\mathrm{r}_{\mathrm{s}}=$ Spearman's rank correlation coefficients. 
from child to child.

According to Piaget's theory of child cognitive development, the sensorimotor stage occurs from birth to 2 year $^{33}$. Children aged $\leq 3$ years may acquire more information $^{3)}$. As sensory and motor signals are inextricably linked ${ }^{34}$, gross motor ability is related to oral sensory processing. Thus, oral sensory processing could be an indicator of gross motor abilities.

A limitation of the current study was that our sample size was small. This also limits the conclusions that were determined by the calculated gross motor ability index within our sample. Additionally, the regression formula obtained in the current study was calculated within our sample. Therefore, it cannot explain the relationships between age and gross motor ability in other age groups. To confirm our results, future studies with larger sample sizes and higher variance among participants are needed.

\section{Conclusion}

The current study revealed that gross motor abilities are related to sensory processing, especially oral sensory processing. Full-term children aged 18 to 36 months with responsiveness in oral sensory processing tended to exhibit gross motor abilities below the standard for that age.

Acknowledgments: We thank Ms. Ayumi Toba, Ms. Miyu Kotani, and Ms. Hiromi Takahashi for their support and arrangements pertaining to the assessments conducted in the current study.

Conflict of Interest: The authors disclose no conflicts of interest.

\section{References}

1) Eeles AL, Spittle AJ, et al.: Assessments of sensory processing in infants: a systematic review. Dev Med Child Neuro. 2013; 55: 314-326.

2) Ahn RR, Miller LJ, et al.: Prevalence of parents' perceptions of sensory processing disorders among kindergarten children. Am J Occup Ther. 2004; 58: 287-293.

3) Dunn W and Daniels DB: Initial Development of the Infant/Toddler Sensory Profile. J Early Intervention. 2002; 25: 27-41.

4) Little ML, Dean E, et al.: Sensory Processing Patterns in Autism, Attention Deficit Hyperactivity Disorder, and Typical Development. Phys Occup Ther Pediatr. 2018; 38: 243-254.

5) Dunn W: Supporting Children to Participate Successfully in Everyday Life by Using Sensory Processing Knowledge. Infants \& Young Children. 2007; 20: 84-101.

6) Hadders-Algra M: Early human motor development: from variation to the ability to vary and adapt. Neurosci Biobehav Rev. 2018; 90: 411-427

7) Smith LB and Thelen E: Development as a dynamic system. Trends Cogn Sci. 2003; 7: 343-348.
8) Spencer JP, Perone S, et al.: Twenty years and going strong: a dynamic systems revolution in motor and cognitive development. Child Dev Perspect. 2011; 5: 260-266.

9) Thelen E: Motor development. A new synthesis. Am Psychol. 1995; 50: 79-95.

10) Hadders-Algra M: The neuronal group selection theory: promising principles for understanding and treating developmental motor disorders. Dev Med Child Neurol. 2000; 42: 707-715.

11) Halil IC, Bulent E, et al.: Investigation of the relationship between sensory processing and motor development in preterm infants. Am J Occup Ther. 2018; 72: 7201195020p1-7.

12) Cabral TI, Pereira da Silva LG, et al.: Motor development and sensory processing: a comparative study between preterm and term infants. Res Dev Disabil. 2015; 36: 102-107.

13) Dunn W: Infant/Toddler Sensory Profile: User's Manual, Psychological Corporation, New York, 2002.

14) Russell DP, Rosenbaum PL, et al.: Gross Motor Function Measure (GMFM-66 \& GMFM-88) user's manual, Mac Keith Press, London, 2002.

15) Hirashima $\mathrm{T}$, Ito $\mathrm{H}$, et al.: Standardization of the Japanese version of the Infant/Toddler Sensory Profile: reliability and cut-off scores based on a community sample. Clinical Psychiatry. 2013; 55: 785-795.

16) Russell D, Palisano R, et al.: Evaluating motor function in children with Down syndrome: validity of the GMFM. Dev Med Child Neuro. 1998; 40: 693-701.

17) Gémus M, Palisano R, et al.: Using the gross motor function measure to evaluate motor development in children with Down syndrome. Phys Occup Ther Pediatr. 2001; 21: 69-79.

18) Linder-Lucht M, Othmer V, et al.: Validation of the Gross Motor Function Measure for use in children and adolescents with traumatic brain injuries. Pediatrics. 2007; 120: e880-e886.

19) Sato T, Adachi M, et al.: The gross motor function measure is valid for Fukuyama congenital muscular dystrophy. Neuromuscul Disord. 2017; 27: 45-49.

20) Wood-Dauphinee S: Reliability of the gross motor function measure for children with osteogenesis imperfecta. Pediatr Phys Ther. 2001; 13: 10-17.

21) Alotaibi M, Long T, et al.: The efficacy of GMFM-88 and GMFM-66 to detect changes in gross motor function in children with cerebral palsy $(\mathrm{CP})$ : a literature review. Disabil Rehabil. 2014; 36: 617-627.

22) Wei S, Su-Juan W, et al.: Reliability and validity of the GMFM66 in 0-to3-year old children with cerebral palsy. Am J Phys Med Rehabil. 2006; 85: 141-147.

23) Brunton LK and Bartlett DJ: Validity and reliability of two abbreviated versions of the gross motor function measure. Phys Ther. 2011; 91: 577-588.

24) Portney LG and Watkins MP: Foundations of clinical research: Applications to practice. 3rd ed, F A Davis Co, Philadelphia, 2015.

25) Roux FE, Djidjeli I, et al.: Functional architecture of the somatosensory homunculus detected by electrostimulation. J Physiol. 2018; 596: 941-956. 
26) Juberg DR, Alfano K, et al.: An observational study of object mouthing behavior by young children. Pediatrics. 2001; 107: 135-142.

27) Ruff HA: Infants' manipulative exploration of objects: effects of age and object characteristics. Dev Psychol. 1984; 20: 9-20.

28) Ruff HA and Dubiner K: Stability of individual differences in infants' manipulation and exploration of objects. Percept Mot Skills. 1987; 64: 1095-1101.

29) Xue J, Zartarian V, et al.: A meta-analysis of children's hand-tomouth frequency data for estimating nondietary ingestion exposure. Risk Anal. 2007; 27: 411-420.

30) Tsou MC, Özkaynak H, et al.: Mouthing Activity Data for Children Aged 7 to 35 Months in Taiwan. J Expo Sci Environ Epide- miol. 2015; 25: 388-398.

31) Tulve NS, Suggs JC, et al.: Frequency of mouthing behavior in young children. J Expo Anal Environ Epidemiol. 2002; 12: 259264.

32) Beamer PI, Luik CE, et al.: Quantified Outdoor Micro-Activity Data for Children Aged 7-12-years Old. Expo Sci Environ Epidemiol. 2012; 22: 82-92.

33) Mussen PH: Carmichael's manual of child psychology. 3rd ed, Vol.1, Jhon Wiley \& Sons, New York, 1970.

34) Huda R, Goard MJ, et al.: Neural mechanisms of sensorimotor transformation and action selection. Eur J Neurosci. 2019; 49: 1055-1060. 